\title{
Influence of the $\mathrm{O}_{2} / \mathrm{CO}$ ratio and the presence of $\mathrm{H}_{2} \mathrm{O}$ and $\mathrm{CO}_{2}$ in the feed-stream during the preferential oxidation of CO (PROX) over a $\mathrm{CuO}_{\mathrm{x}} / \mathrm{CeO}_{2}$-coated microchannel reactor
}

\section{O.H. Laguna ${ }^{1}$, M.I. Domínguez ${ }^{1}$, S. Oraá ${ }^{1}$, A. Navajas ${ }^{2}$, G. Arzamendi ${ }^{2}$, L.M.} Gandía $^{2}$, M.A. Centeno ${ }^{1}$, M. Montes ${ }^{3}$ and J.A. Odriozola ${ }^{1}$

${ }^{1}$ Departamento de Química Inorgánica e Instituto de Ciencia de Materiales de Sevilla, Centro Mixto CSIC-Universidad de Sevilla, Avda. Américo Vespucio 49, 41092 Sevilla, Spain

${ }^{2}$ Departamento de Química Aplicada, Edificio de los Acebos, Universidad Pública de Navarra, Campus de Arrosadía s/n, E-31006, Pamplona, Spain

${ }^{3}$ Departamento de Química Aplicada, Facultad de Ciencias Químicas de San Sebastián, Universidad del País Vasco, $P^{o}$ Manuel de Lardizábal 3, E-20018, San Sebastián, Spain

*Corresponding author: oscarh@icmse.csic.es

\begin{abstract}
The catalytic performance of a $\mathrm{CuO}_{\mathrm{x}} / \mathrm{CeO}_{2}$ powder catalyst and that of a microchannel reactor or microreactor (MR) coated with the same solid were determined and compared. The catalytic activity measurements were carried out with varying $\mathrm{O}_{2} / \mathrm{CO}$ molar ratios in the feed-stream. In addition, the influence of the presence of $\mathrm{CO}_{2}$ and $\mathrm{H}_{2} \mathrm{O}$ in the reaction mixture was studied. Some discrepancies were observed between the performances of the powder catalyst and the MR depending on the $\mathrm{O}_{2} / \mathrm{CO}$ ratio. The
\end{abstract}


MR presented a very good performance with a superior selectivity for CO conversion. This behaviour was due to a more efficient heat removal in the case of the MR that inhibited the $\mathrm{H}_{2}$ oxidation reaction and the r-WGS. The isothermicity of the microreactor during the process was demonstrated through the monitoring of the MR inlet and outlet temperatures.

Concerning the presence of $\mathrm{CO}_{2}$ or $\mathrm{H}_{2} \mathrm{O}$ in the feed-stream, both compounds gave rise to a decrease of the $\mathrm{CO}$ conversion. The negative effect on the catalytic performance was more marked when both compounds were fed together, although the principal inhibitor effect was associated to the $\mathrm{CO}_{2}$. This seems to be related with the formation of stable carbonates at the catalyst surface.

\section{Keywords}

Microchannel reactor; Hydrogen purification; PROX, CO oxidation; $\mathrm{Cu}$-modified ceria

\section{Introduction}

Global warming caused by the emission of greenhouse gases and the need of alternative energy sources for sustaining the present energy demand, are problems showing the need to rethink our way of life $[1,2]$. In this sense, the using of fuels other than the fossil ones is an interesting alternative. For example using renewable $\mathrm{H}_{2}$ for feeding electric and electronic devices that employ fuel cells such as the proton exchange membrane (PEMFC) type, is a promising option from the environmental point of view $[3,4]$. However, the application of PEMFCs requires the use of highly pure $\mathrm{H}_{2}$ with very low $\mathrm{CO}$ contents $(<20 \mathrm{ppm})$ [5]. When $\mathrm{H}_{2}$ is produced through the reforming of hydrocarbons and alcohols, the preferential oxidation of CO (PROX) is one of the possible processes that can be applied for the final cleaning after preliminary 
purification in the high and low temperature water-gas shift (WGS) [6-8]. As for the PROX reaction, several catalysts have been proposed and the solids based on $\mathrm{CuO}_{\mathrm{x}} / \mathrm{CeO}_{2}$ mixture are among the most studied materials due to their excellent performance for the $\mathrm{CO}$ conversion $[9,10]$. However a crucial issue for the PROX reaction is broadening the operating temperature window of maximum $\mathrm{CO}$ conversion with high selectivity, considering the presence of other reactions that can simultaneously occur $\left(\mathrm{H}_{2}\right.$ oxidation and the reverse-water-gas shift (r-WGS)) [11].

On the other hand, from a technological point of view, when the PEMFCs are employed for portable or automotive applications, the use of conventional reactors for producing and cleaning the required $\mathrm{H}_{2}$ represents several drawbacks such us pressure drop along the catalyst bed, temperature gradients, hot spot formation due to the high exothermicity of the $\mathrm{CO}$ and $\mathrm{H}_{2}$ oxidation reactions and size weight issues $[12,13]$. In this regard, microreactors are promising devices that have the advantages of fast response time, easy integration, and small footprint, which are ideal for portable and on-board power systems [14]. Additionally, the mass and heat transport rates are greatly increased in these devices $[12,13,15,16]$, being crucial for the PROX reaction, no matter the catalyst employed, because it requires a careful temperature control due to the exothermicity of the main reactions involved.

In this context, the principal aim of this work is to evaluate the performance of a $\mathrm{CuO}_{\mathrm{x}} / \mathrm{CeO}_{2}$ coated microreactor for the $\mathrm{CO}-\mathrm{PROX}$ reaction and comparing it with that of the $\mathrm{CuO}_{\mathrm{x}} / \mathrm{CeO}_{2}$ catalyst in powder form employing different feed-stream compositions, specifically modifying the $\mathrm{O}_{2} / \mathrm{CO}$ molar ratio. The effect of $\mathrm{H}_{2} \mathrm{O}$ and $\mathrm{CO}_{2}$ is also studied in order to establish the catalytic activity of the microreactor under realistic conditions, that is, using PROX feed-stream compositions that simulate the composition of a reformate off-gas after exiting the WGS units. 


\section{Materials and methods}

The synthesis of the $\mathrm{CuO}_{\mathrm{x}} / \mathrm{CeO}_{2}$ powder catalyst was carried out by coprecipitation employing suitable amounts of $\mathrm{Cu}\left(\mathrm{NO}_{3}\right)_{2}$ and $\mathrm{Ce}\left(\mathrm{NO}_{3}\right)_{3}$ in order to achieve a 9:1 $\mathrm{Ce}(\mathrm{OH})_{3}: \mathrm{Cu}(\mathrm{OH})_{2}$ weight ratio after the addition of $\mathrm{NaOH}(2 \mathrm{M})$. The obtained solid washed with distilled water and dried at $60{ }^{\circ} \mathrm{C}$ overnight, and finally calcined for $2 \mathrm{~h}$ at $300{ }^{\circ} \mathrm{C}[17,18]$.

The details of the MR manufacturing (micromachining and joining of the steel plates), and assembly have been recently reported [17]. Washcoating was selected for coating the microchannels with the $\mathrm{CuO}_{\mathrm{x}} / \mathrm{CeO}_{2}$ catalyst using a slurry with the following composition: 76 wt.\% powder $\mathrm{CuO}_{\mathrm{x}} / \mathrm{CeO}_{2}$ catalyst, 7 wt.\% polyvinyl alcohol (PVOH) and 17 wt.\% colloidal alumina. The $\mathrm{pH}$ of the suspension was adjusted to 4 with diluted $\mathrm{HNO}_{3}[17,19,20]$.

Once the microchannels were immersed in the slurry, the elimination of excess was done by air blowing ( $2 \mathrm{~L} / \mathrm{min}$ ). After each coating process, the microchannel block was dried at $120{ }^{\circ} \mathrm{C}$ for $30 \mathrm{~min}$ and finally calcined at $300{ }^{\circ} \mathrm{C}$ for $3 \mathrm{~h}\left(1{ }^{\circ} \mathrm{C} / \mathrm{min}\right)$. This method resulted in a microchannel block loading of $5.46 \mathrm{mg} / \mathrm{cm}^{2}$ after eight washcoating processes, with a total load of $300 \mathrm{mg}$ of catalyst [17].

Concerning to the catalytic activity measurements, prior to every test the catalyst (both in the powder form and in the microreactor) was activated under $30 \mathrm{~mL} / \mathrm{min}$ total flow of $21 \% \mathrm{O}_{2}$ in $\mathrm{N}_{2}$ at $300{ }^{\circ} \mathrm{C}$ for $2 \mathrm{~h}$.

As for the powder catalyst, the PROX reaction was carried out at atmospheric pressure on a cylindrical stainless steel reactor ( $9 \mathrm{~mm}$ inner diameter), with $100 \mathrm{~mL} / \mathrm{min}$ total flow of the mixture of reaction. The catalyst powder $(100 \mathrm{mg}$, particle size $\varnothing=100-200$ $\mu \mathrm{m})$ was diluted with crushed inert glass with the same particle size until a reactor bed 
height of $5 \mathrm{~mm}$. The temperature of the reaction was recorded by a thermocouple $\mathrm{K}$ type whose top was in contact with the top of the fixed bed.

In the case of the microreactor, the temperature was continuously monitored by $4 \mathrm{~K}$ type thermocouples. Two of them were placed in contact with the metallic block at the inlet and outlet positions of some central microchannels. The other two sensors recorded the temperature at lateral positions in the walls of the microblock [18].

For the two evaluated catalytic systems, the products and reactants were analyzed by online gas chromatography (Agilent ${ }^{\circledR} 7890$ equipped with a Porapak ${ }^{\circledR}$ Q, two Molecular Sieve 5A, and two Hayesep ${ }^{\circledR} \mathrm{Q}$ columns) and then quantified using a TCD detector. The $\mathrm{CO}$ conversion and the selectivity to $\mathrm{CO}$ conversion were calculated according to Equations 1 and 2, respectively, where $F_{\text {in }}$ and $F_{\text {out }}$ refer to molar flow rates at the reactor entry and outlet, respectively [21].

$$
\text { CO conversion }(\%)=\frac{\left(F_{C O, \text { in }}-F_{C O, \text { out }}\right) \times 100}{F_{C O, \text { in }}}
$$

$$
\text { Selectivity to CO conversion }(\%)=\frac{\left(F_{C O_{\text {, in }}}-F_{C O_{\text {out }}}\right) \times 100}{2\left(F_{\mathrm{O}_{2}, \text { in }}-F_{\mathrm{O}_{2}, \text { out }}\right)}
$$

In order to compare the catalytic activity of the $\mathrm{CuO}_{\mathrm{x}} / \mathrm{CeO}_{2}$ powder catalyst $(100 \mathrm{mg})$ and that of the microreactor, the variation of the $\mathrm{O}_{2} / \mathrm{CO}$ molar ratio and the presence of $\mathrm{H}_{2} \mathrm{O}$ and $\mathrm{CO}_{2}$ feed-stream were studied. To this end, the several feed-stream compositions included in Table 1 were employed $\left(\mathrm{N}_{2}\right.$ was used as balance). The oxygen excess in the reaction mixture was defined as a factor $(\lambda)$, according to Eq. 3, taking into account that the stoichiometric amounts of $\mathrm{CO}$ and $\mathrm{O}_{2}$ present a $\lambda=1$. This $\lambda$ factor has been previously applied by other authors in the study of different feed-stream composition for PROX reaction [22]. 


$$
\lambda=\frac{2 \times F_{\mathrm{O}_{2}, \text { in }}}{F_{\mathrm{CO}, \mathrm{in}}}
$$

Total flow rate was $100 \mathrm{~mL} \cdot \mathrm{min}^{-1}$ for the powder catalyst and $300 \mathrm{~mL} \cdot \mathrm{min}^{-1}$ for the microreactor in order to achieve the same total flow $\left(\mathrm{L} \cdot \mathrm{h}^{-1}\right)$ to weight of catalyst $(\mathrm{g})$ ratio in both cases $\left(60 \mathrm{~L} \cdot \mathrm{h}^{-1} \cdot \mathrm{g}^{-1}\right)$.

\section{Results and discussion}

\subsection{Influence of the $\mathrm{O}_{2} / \mathrm{CO}$ molar ratio in the feed-stream}

A comparison between the catalytic behaviour of the microchannel reactor and that of the $\mathrm{CuO}_{\mathrm{x}} / \mathrm{CeO}_{2}$ powder catalyst as a function of the $\lambda$ factor was carried out employing the feed-stream compositions 1-4 (Table 1). The results of $\mathrm{CO}$ conversion and selectivity to $\mathrm{CO}$ oxidation are presented in Figs. 1 and 2, respectively.

Both systems show similar general trends. CO conversion increases with temperature until reaching a plateau at $160^{\circ} \mathrm{C}$ irrespective of the $\mathrm{O}_{2} / \mathrm{CO}$ ratio employed.

The powder catalyst shows a slightly superior catalytic activity than the microreactor at temperatures below $160{ }^{\circ} \mathrm{C}$ at $\lambda$ factors (1.5) slightly above the stoichiometric one (1). However, the microreactor gives higher $\mathrm{CO}$ conversions when the proportion of $\mathrm{O}_{2}$ increases up to $\lambda \geq 4$. For that reason the results are presented in two figures (Figure 1a and $1 \mathrm{~b}$ ), because the higher excess of $\mathrm{O}_{2}$ seems to improve the performance of the microreactor.

Considering that not significant changes in the chemical nature of the catalyst were noticeable after the washcoating, as demonstrated by the characterization of the microreactor presented in [17], the observed superior catalytic activity of the microreactor under $\mathrm{O}_{2}$ excess conditions, could be related with changes of the mass and 
heat transfer rates when using the microreactor compared with the packed bed of powder catalyst. It has to be pointed out that the exothermicity of the $\mathrm{CO}$ and $\mathrm{H}_{2}$ oxidations does not depend on the extension of these reactions. Thus, the amount of heat released is a function only of the catalytic performances of the catalyst and not of their nature.

On the other hand, the microreactor allows a more efficient contact between the catalyst surface and the reaction mixture. This favours products release, which is continuously shifting the equilibrium to the $\mathrm{CO}_{2}$ formation. It means that the mass transport phenomena can be enhanced for the microreactor with respect to the fixed bed reactor. However, this cannot be directly established with an in-situ characterization technique because the access to the microchannels requires the destruction of the block, which implies the modification of the catalyst. For that reason the mass transport phenomena are not deeply described in the present work. However complementary works are being carried out with the aim of establishing a correlation between the amount of loaded catalyst and the catalytic activity of the microreactor. On the other hand, an in-situ DRIFT study under reaction PROX conditions has been carried out over some plates of the same material than that of the microreactor (ferritic stainless steel-Fecralloy ${ }^{\circledR}$ ) and coated with the $\mathrm{CuO}_{\mathrm{x}} / \mathrm{CeO}_{2}$ catalyst. The obtained results are currently under analysis and will be published in the near future.

Concerning the selectivity for the oxidation of $\mathrm{CO}$, it decreases with the temperature (see Figure 2), which demonstrates that the $\mathrm{H}_{2}$ oxidation is improved at higher temperatures. These results agree with previous studies where the behaviour of the $\mathrm{CuO}_{\mathrm{x}} / \mathrm{CeO}_{2}$ catalysts in this reaction has been investigated [7, 8]. In addition, the activation energy values obtained in the kinetic study by Arzamendi et al. [6] of the COPROX reaction over the $\mathrm{CuO}_{\mathrm{x}} / \mathrm{CeO}_{2}$ catalyst loaded in the catalytic-wall microreactor of 
the present study where $110 \mathrm{~kJ} \cdot \mathrm{mol}^{-1}$ for the $\mathrm{H}_{2}$ oxidation reaction and $36.9 \mathrm{~kJ} \cdot \mathrm{mol}^{-1}$ for the oxidation of $\mathrm{CO}$. This explains the fact that as the temperature increases, the oxidation of $\mathrm{H}_{2}$ is much more favoured than that of $\mathrm{CO}$ thus leading to a selectivity decrease.

On the other hand, although more points would be required for the generation of more complete trends, the MR provides higher selectivities than the powder catalyst whatever the $\mathrm{O}_{2} / \mathrm{CO}$ ratio (see Figure 2). This evidences that the MR is more efficient for the PROX reaction because similar $\mathrm{CO}$ conversion levels were obtained with less $\mathrm{H}_{2}$ consumption, especially at low temperatures and high $\mathrm{O}_{2} / \mathrm{CO}$ molar ratios. The possibility of getting a more efficient heat transport during the PROX reaction can be considered as a possible cause contributing to achieve a higher selectivity in the case of the MR.

The positive effects of using the catalytic microreactor are more evident if the selectivity is represented as a function of the $\mathrm{CO}$ conversion (see Fig. 3).

In the case of the powder catalyst, it can be observed that the excess of $\mathrm{O}_{2}$ decreases both the maximum $\mathrm{CO}$ conversion and the selectivity for $\mathrm{CO}$ oxidation. However the MR keeps the maximum selectivity levels even at high oxygen excess in the feedstream, and CO conversion as high as $98 \%$. A further increase of the CO conversion leads to a marked decrease of the selectivity; these values correspond to reaction temperatures near $200{ }^{\circ} \mathrm{C}$ that strongly enhance the $\mathrm{H}_{2}$ oxidation. In general, the $\mathrm{MR}$ allows working with a wider operating temperatures window for acceptable $\mathrm{CO}$ conversion and selectivity.

A similar behaviour was observed by Ouyang et al. [23] on a silicon microchannel reactor fabricated by means of a micromachining process [24] and employing a $\mathrm{Pt} / \mathrm{Al}_{2} \mathrm{O}_{3}$ catalyst synthesized by a sol-gel method. In this work, it was demonstrated 
through simulations generated from a kinetic model, that for mini-packed reactors some temperature gradients may be noticeable during the CO-PROX reaction. These gradients favour the reverse water-gas-shift (r-WGS) reaction, thus narrowing the range of temperatures where a high CO conversion is achieved with high selectivities. But in the case of the silicon microchannel reactors, more efficient heat removal was appreciated, which prevents the r-WGS reaction. This means that, as in our case, the generation of a catalytic thin layer covering the walls of the microchannels allows an efficient heat release during the reaction and this would be the key for achieving not only a high $\mathrm{CO}$ conversion but also a high selectivity.

The exothermicity of the $\mathrm{CO}$ and $\mathrm{H}_{2}$ oxidation reactions $\left(-283\right.$ and $-242 \mathrm{~kJ} \cdot \mathrm{mol}^{-1}$, respectively) determines that the thermal management is a key aspect of the design of the PROX reactors as confirmed by studies such as the one reported by Roberts et al. [25], in which the r-WGS reaction occurrence was analysed in an adiabatic monolith reactor during the CO-PROX. In this work it was observed that the complete conversion of $\mathrm{O}_{2}$ generates an important increase of the temperature until $300{ }^{\circ} \mathrm{C}$ for an inlet temperature of $170{ }^{\circ} \mathrm{C}$. A similar behaviour could be considered for the powder catalysts that present a poor thermal conductivity. However, in the microreactor, the small thickness of the catalytic layer allows reducing the distance for the radial heat conduction [23]. In this regard, the selection of the material for manufacturing the microchannel reactor is also crucial in order to ensure a rapid heat transfer during the reaction. In our case the ferritic stainless FeCrAlloy ${ }^{\circledR}$ results adequate for this purpose. In a recent report [6] we developed a computational fluid dynamics (CFD) model for the same MR considered in this study that was successfully validated with experimental data in [18]. With this model the temperature profiles of the fluidic and solids domains were obtained considering the possibility of cooling the reactor with air passing through 
a portion of the channels. A very uniform temperature profile is established along the solid domain, without big differences between the inlet and outlet temperatures.

The isothermicity of the MR during the PROX reaction can be confirmed experimentally through the monitoring of the inlet and outlet temperatures with the two thermocouples that are placed at these microreactor positions. As representative examples, the inlet and outlet temperatures recorded during a PROX reaction at $160{ }^{\circ} \mathrm{C}$ (as the set temperature) using two different $\lambda$ factors are presented in Fig. 4.

The data recording started with the feed-stream passing through the reactor bypass. The reaction started after switching a valve that allowed the access of the feed-stream to the microchannels is indicated by the dashed lines of Fig. 4. The initial difference between the inlet and outlet temperatures is less than $1{ }^{\circ} \mathrm{C}$ and it is attributed to the precision of the sensors. The reaction increases both temperatures but the difference respect to the set value $\left(160{ }^{\circ} \mathrm{C}\right)$ is not superior to 2 or $3{ }^{\circ} \mathrm{C}$ and the system tends to be quickly stabilized at the set temperature value. The heat is rapidly released which allows achieving a strict control of the reaction temperature.

Concerning the influence of the presence of $\mathrm{CO}_{2}$ in the feed-stream, we have previously discussed results for the same MR that is being studied in this work. Using 10 vol.\% $\mathrm{CO}_{2}$ it was pointed out that this compound was the principal inhibitor of the CO-PROX reaction. In the present study, different proportions of $\mathrm{CO}_{2}$ have been considered (compositions 3, 5-7 - see Table 1) and the results are shown in Fig. 5. In this case the catalytic activity is presented not as the $\mathrm{CO}$ conversion but as the $\mathrm{CO}$ content (ppmv) at the MR outlet.

These results demonstrate that there is a temperature or even a range of temperatures $\left(160-200{ }^{\circ} \mathrm{C}\right)$ where the $\mathrm{CO}$ content presents a minimum value for all the studied feedstream compositions. However, when $\mathrm{CO}_{2}$ is present in the feed-stream, the $\mathrm{CO}$ content 
at temperatures below $200{ }^{\circ} \mathrm{C}$ increases and the operating temperature window for acceptable CO conversion becomes narrow. There are not big differences irrespective of the $\mathrm{CO}_{2}$ proportion, especially above $200{ }^{\circ} \mathrm{C}$. However, this behaviour is modified after the introduction of $\mathrm{H}_{2} \mathrm{O}$ in the feed-stream (compositions 8-10 in Table 1). The results are presented in Fig. 6.

As in the previous case, the $\mathrm{CO}$ content at the MR outlet increases with the amount of $\mathrm{CO}_{2}$. However, the emitted $\mathrm{CO}$ concentration is higher in presence of $\mathrm{H}_{2} \mathrm{O}$, suggesting that when both $\mathrm{CO}_{2}$ and $\mathrm{H}_{2} \mathrm{O}$ are fed there is an increased inhibition of the $\mathrm{CO}$ conversion.

Recently, we found that the presence of 10 vol. $\% \mathrm{H}_{2} \mathrm{O}$ protects the $\mathrm{CuO}_{\mathrm{x}} / \mathrm{CeO}_{2}$ coated MR of the inhibition caused otherwise by the presence of 10 vol.\% $\mathrm{CO}_{2}$ in the feedstream [18]. However, these experiments were carried out employing a higher oxygen excess with respect to the $\mathrm{CO}$ content $\left(\mathrm{O}_{2} / \mathrm{CO}=2\right)$, than that used in the catalytic tests presented here $\left(\mathrm{O}_{2} / \mathrm{CO}=1\right.$, see Table 1$)$. This means that the $\mathrm{O}_{2} / \mathrm{CO}$ ratio in the feedstream also influences the loss of activity of the catalyst by the adsorption of $\mathrm{H}_{2} \mathrm{O}$ and $\mathrm{CO}_{2}$, which could compete with the $\mathrm{CO}$ for being adsorbed on the active sites. The negative effect of $\mathrm{H}_{2} \mathrm{O}$ and $\mathrm{CO}_{2}$ has been discussed by other authors such as Lee et al. [26] in their kinetic study with a $\mathrm{CuO}_{\mathrm{x}} / \mathrm{CeO}_{2}$ powder catalyst of the CO-PROX reaction. In this report it was demonstrated that the rate of the $\mathrm{CO}$ and $\mathrm{H}_{2}$ oxidation reactions are dependent of the partial pressure of $\mathrm{CO}_{2}$ and $\mathrm{H}_{2} \mathrm{O}$ resulting in negative reaction orders with respect to the partial pressures of these compounds.

On the other hand, considering the highly reducing character of the PROX environment, the presence of metallic copper and $\mathrm{Ce}^{3+}$ species is expected according to the reducibility studies carried out with the powder catalysts. The reduced cerium species 
may give rise to the formation of stable carbonates and this can be the reason of the strong inhibition of the $\mathrm{CO}$ conversion caused by $\mathrm{CO}_{2}$.

According to these results, a more efficient desorption of $\mathrm{CO}_{2}$ from catalyst would improve the catalytic performance prolonging the life time of the microreactor. It is possible that the enhancement of the mass transport rates during the reaction owing to the very short diffusion distances prevailing in the catalytic wall MR compared with the powder catalyst may allow a faster release of the $\mathrm{CO}_{2}$ species. However this point has to be confirmed with complementary studies that are currently in progress in our laboratories.

\section{Conclusions}

After the comparison of the catalytic performance of the $\mathrm{CuO}_{\mathrm{x}} / \mathrm{CeO}_{2}$ catalyst in powder and that of a microreactor that was coated with this catalyst, the second one system presents similar CO conversion levels than the powder but with a superior selectivity. Under high oxygen excess in the feed-stream $(\lambda=4$ and 6.7$)$, the microreactor not only presents a superior selectivity but also a high CO conversion at temperatures below 160 ${ }^{\circ} \mathrm{C}$. Although the improvement of the catalytic activity and selectivity in the microreactor can also be associated to some changes in the mass transport phenomena, the more evident contribution is the achieving of a very efficient heat transport during reaction, which is improving the $\mathrm{CO}$ oxidation and inhibits the $\mathrm{H}_{2}$ oxidation and the RWGS reactions. The microreactor allows obtaining a good control of the set temperature of the reaction, which in the case of this highly exothermic process results crucial for the avoiding of hot spots in the reaction environment.

Concerning the presence of $\mathrm{CO}_{2}$ and $\mathrm{H}_{2} \mathrm{O}$, both compounds generate a decrease of the catalytic activity of the coated $\mathrm{CuO}_{\mathrm{x}} / \mathrm{CeO}_{2}$ solid, may be because they are competing with $\mathrm{CO}$ for becoming adsorbed on the active sites. Nevertheless, the $\mathrm{CO}_{2}$ produces a 
stronger inhibitor effect, probably due to the formation of carbonaceous species over the catalytic surface, especially metallic carbonates that would be blocking the active sites.

\section{Acknowledgments}

Financial support for this work has been obtained from the Spanish Ministerio de Ciencia e Innovación (ENE2009-14522-C05-01) co-financed by FEDER funds from the European Union, and from Junta de Andalucía (P09-TEP-5454). O.H. Laguna thanks the same Ministry for the FPI fellowship (BES-2007-14409) awarded.

\section{References}

[1] W. Dougherty, S. Kartha, C. Rajan, M. Lazarus, A. Bailie, B. Runkle, and A. Fencl, Energy Policy 37 (2009) 56.

[2] Z. Li, D. Gao, L. Chang, P. Liu, and E. N. Pistikopoulos, International Journal of Hydrogen Energy 33 (2008) 5275.

[3] O. J. Kwon, S.-M. Hwang, J. H. Chae, M. S. Kang, and J. J. Kim, Journal of Power Sources 165 (2007) 342.

[4] S. M. De Lima, R. C. Colman, G. Jacobs, B. H. Davis, K. R. Souza, A. F. F. De Lima, L. G. Appel, L. V. Mattos, and F. B. Noronha, Catalysis Today 146 (2009) 110.

[5] B. Rohland and V. Plzak, Journal of Power Sources 84 (1999) 183.

[6] G. Arzamendi, I. Uriz, P. M. Diéguez, O. H. Laguna, W. Y. Hernández, A. Álvarez, M. A. Centeno, J. A. Odriozola, M. Montes, and L. M. Gandía, Chemical Engineering Journal 167 (2011) 588. 
[7] A. Martínez-Arias, A. B. Hungría, M. Fernández-García, J. C. Conesa, and G. Munuera, Journal of Power Sources 151 (2005) 32.

[8] A. Martínez-Arias, A. B. Hungría, G. Munuera, and D. Gamarra, Applied Catalysis B: Environmental 65 (2006) 207.

[9] D. Gamarra and A. Martínez-Arias, Journal of Catalysis 263 (2009) 189.

[10] A. Martínez-Arias, M. Fernández-García, O. Gálvez, J. M. Coronado, J. A. Anderson, J. C. Conesa, J. Soria, and G. Munuera, Journal of Catalysis 195 (2000) 207.

[11] Y. Zhang, H. Liang, X. Y. Gao, and Y. Liu, Catalysis Communications 10 (2009) 1432.

[12] D. I. Potemkin, P. V. Snytnikov, V. D. Belyaev, and V. A. Sobyanin, Chemical Engineering Journal 176-177 (2011) 165.

[13] P. V. Snytnikov, D. I. Potemkin, E. V. Rebrov, V. A. Sobyanin, V. Hessel, and J. C. Schouten, Chemical Engineering Journal 160 (2010) 923.

[14] M. O'Connell, G. Kolb, K.-P. Schelhaas, J. Schuerer, D. Tiemann, A. Ziogas, and V. Hessel, International Journal of Hydrogen Energy 35 (2010) 2317.

[15] G. Kolb and V. Hessel, Chemical Engineering Journal 98 (2004) 1.

[16] G. Kolb, C. Hofmann, M. O'Connell, and J. Schürer, Catalysis Today 147 (2009) S176. 
[17] S. Cruz, O. Sanz, R. Poyato, O. H. Laguna, F. J. Echave, L. C. Almeida, M. A. Centeno, G. Arzamendi, L. M. Gandía, E. F. Souza-Aguiar, M. Montes, and J. A. Odriozola, Chemical Engineering Journal 167 (2011) 634.

[18] O. H. Laguna, E. M. Ngassa, S. Oraá, A. Álvarez, M. I. Domínguez, F. RomeroSarria, G. Arzamendi, L. M. Gandía, M. A. Centeno, and J. A. Odriozola, Catalysis Today 180 (2012) 105.

[19] L. C. Almeida, F. J. Echave, O. Sanz, M. A. Centeno, G. Arzamendi, L. M. Gandía, E. F. Sousa-Aguiar, J. A. Odriozola, and M. Montes, Chemical Engineering Journal 167 (2011) 536.

[20] L. C. Almeida, F. J. Echave, O. Sanz, M. A. Centeno, J. A. Odriozola, and M. Montes, Studies in Surface Science and Catalysis 175 (2010) 25.

[21] O. H. Laguna, F. Romero Sarria, M. A. Centeno, and J. A. Odriozola, Journal of Catalysis $276(2010) 360$.

[22] N. Bion, F. Epron, M. Moreno, F. Mariño, and D. Duprez, Topics in Catalysis $51(2008) 76$.

[23] X. Ouyang and R. S. Besser, Journal of Power Sources 141 (2005) 39.

[24] R. Besser and W. Shin, J. Vac. Sci. Technol. B 21 (2003) 912.

[25] G. W. Roberts, P. Chin, X. Sun, and J. J. Spivey, Applied Catalysis B: Environmental 46 (2003) 601.

[26] H. C. Lee and D. H. Kim, Catalysis Today 132 (2008) 109. 

TABLE

Table 1. Feed-stream compositions (vol.\%) used in the catalytic tests

\begin{tabular}{cccccccc}
\hline Composition & $\mathrm{CO}$ & $\mathrm{O}_{2}$ & $\mathrm{CO}_{2}$ & $\mathrm{H}_{2} \mathrm{O}$ & $\mathrm{H}_{2}$ & $\mathrm{~N}_{2}$ & $\lambda$ \\
\hline 1 & 0.3 & 1.0 & -- & -- & 50.0 & 48.7 & 6.7 \\
2 & 0.5 & 1.0 & -- & -- & 50.0 & 48.5 & 4 \\
3 & 1.0 & 1.0 & -- & -- & 50.0 & 48.0 & 2 \\
4 & 2.0 & 1.5 & -- & -- & 50.0 & 46.5 & 1.5 \\
5 & 1.0 & 1.0 & 2.0 & -- & 50.0 & 46.0 & 2 \\
6 & 1.0 & 1.0 & 5.0 & -- & 50.0 & 43.0 & 2 \\
7 & 1.0 & 1.0 & 10.0 & -- & 50.0 & 38.0 & 2 \\
8 & 1.0 & 1.0 & 2.0 & 10.0 & 50.0 & 36.0 & 2 \\
9 & 1.0 & 1.0 & 5.0 & 10.0 & 50.0 & 33.0 & 2 \\
10 & 1.0 & 1.0 & 10.0 & 10.0 & 50.0 & 28.0 & 2 \\
\hline
\end{tabular}




\section{FIGURE CAPTIONS}

Figure 1. CO conversion as a function of the $\lambda$ factor in the feed-stream and the reaction temperature for the powder catalyst and the microreactor (MR) $[\lambda$ : (a) 2 and 1.5; (b) 6.7 and 4].

Figure 2. Selectivity for $\mathrm{CO}$ oxidation as a function of the $\lambda$ factor in the feed-stream and the reaction temperature for the powder catalyst and the microreactor (MR) $[\lambda$ : (a) 2 and 1.5 ; (b) 6.7 and 4$]$.

Figure 3. Selectivity for $\mathrm{CO}$ oxidation as a function of the $\lambda$ factor in the feed-stream and the $\mathrm{CO}$ conversion for the powder catalyst and the microreactor (MR)

Fig.4. Monitoring of the inlet and outlet temperatures during a catalytic test with the MR at $160^{\circ} \mathrm{C}$ using different $\lambda$ factors: (a) 4; (b) 2 .

Figure 5. Effect of the presence of $\mathrm{CO}_{2}$ in the feed-stream and the reaction temperature on the CO content at the CO-PROX microreactor outlet.

Figure 6. Effect of the presence $\mathrm{CO}_{2}$ and $\mathrm{H}_{2} \mathrm{O}$ in the feed-stream and the reaction temperature on the $\mathrm{CO}$ content at the CO-PROX microreactor outlet. 


\section{FIGURES}

(a)

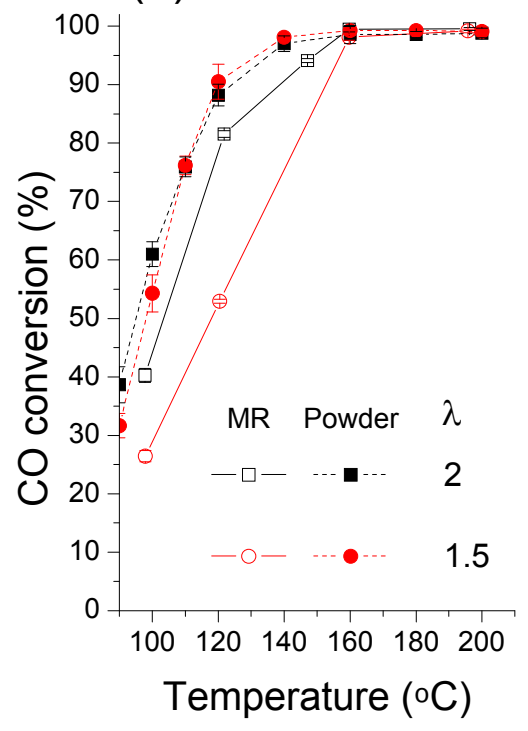

(b)

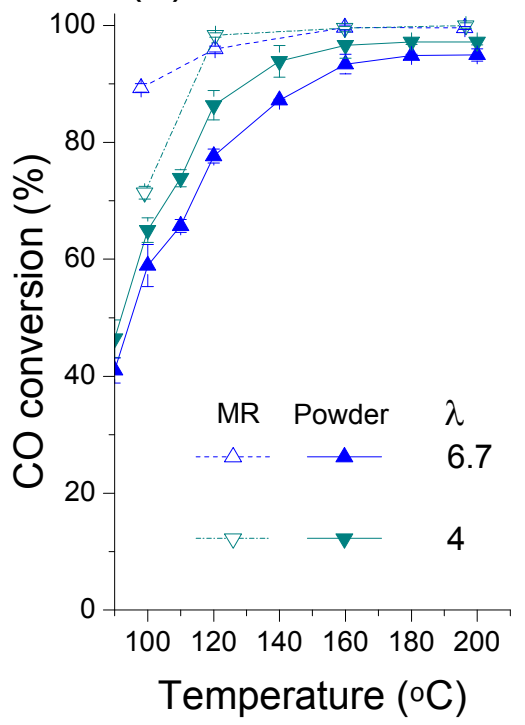

Figure 1 

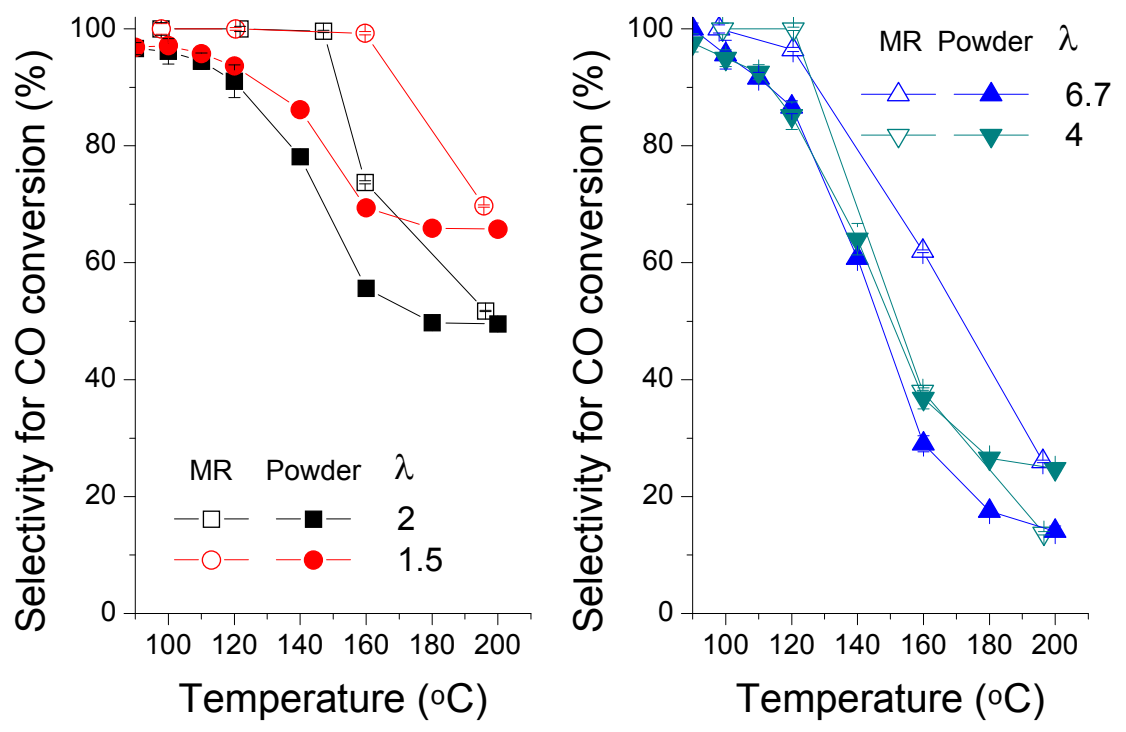

Figure 2 


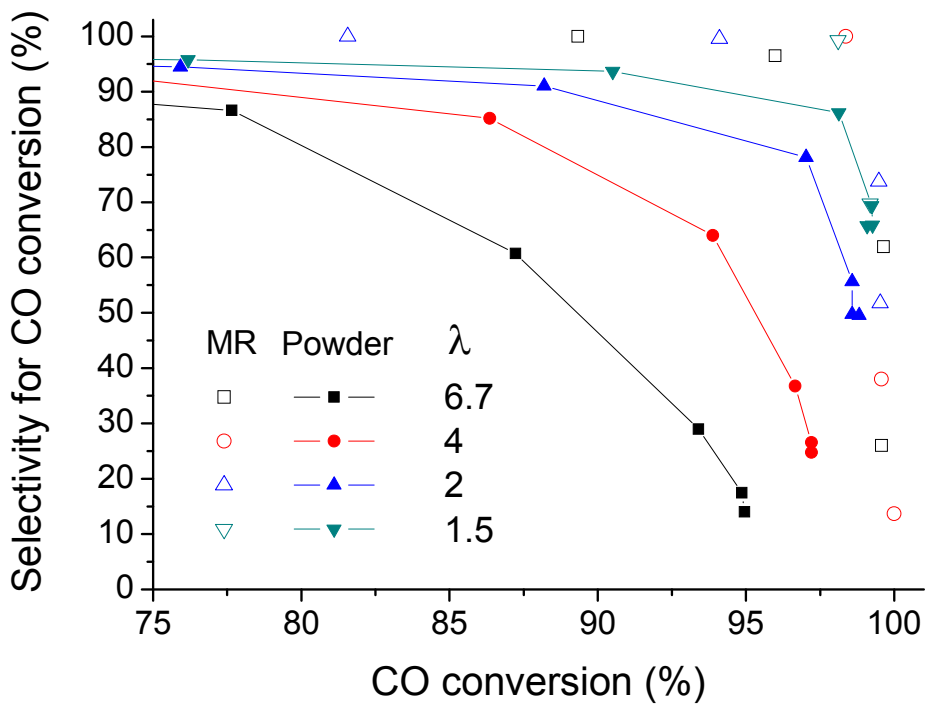

Figure 3 
(a)
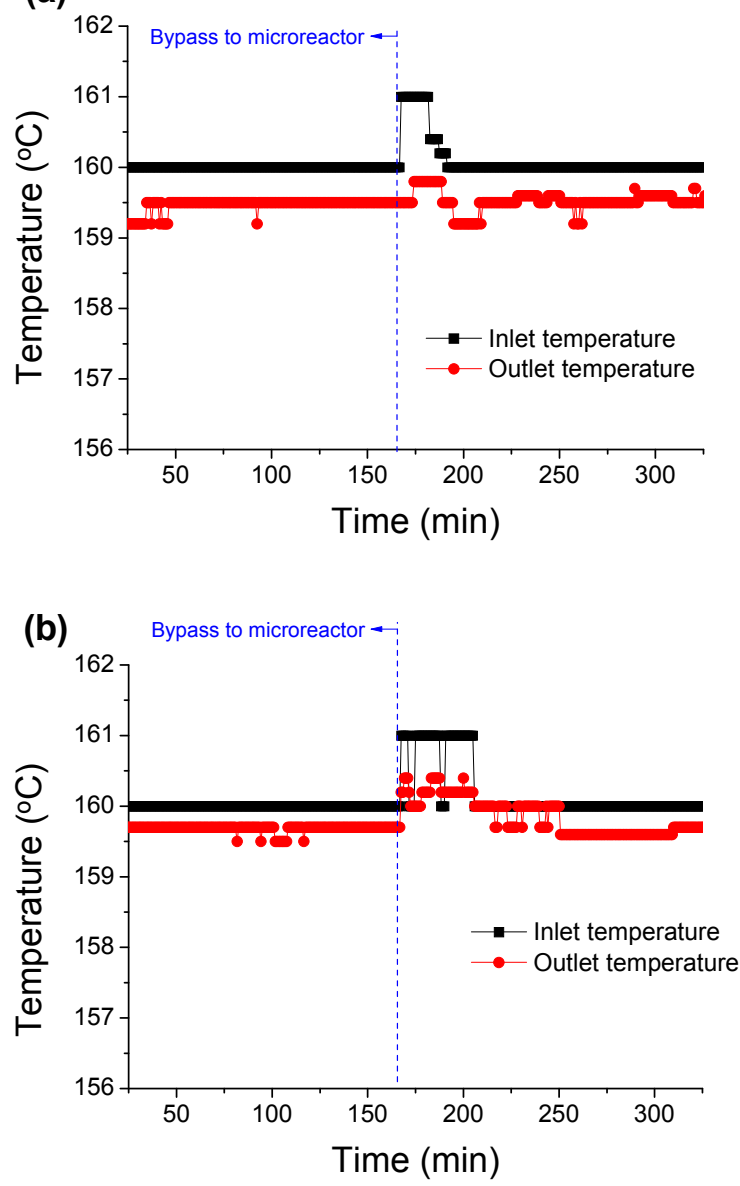

Figure 4 


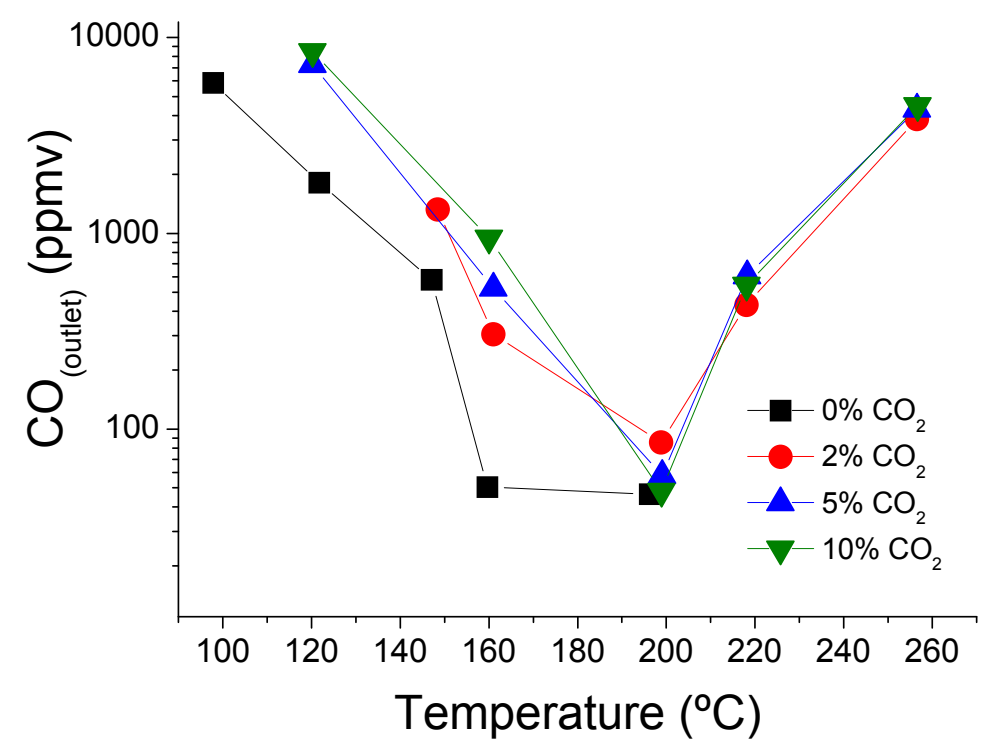

Figure 5 


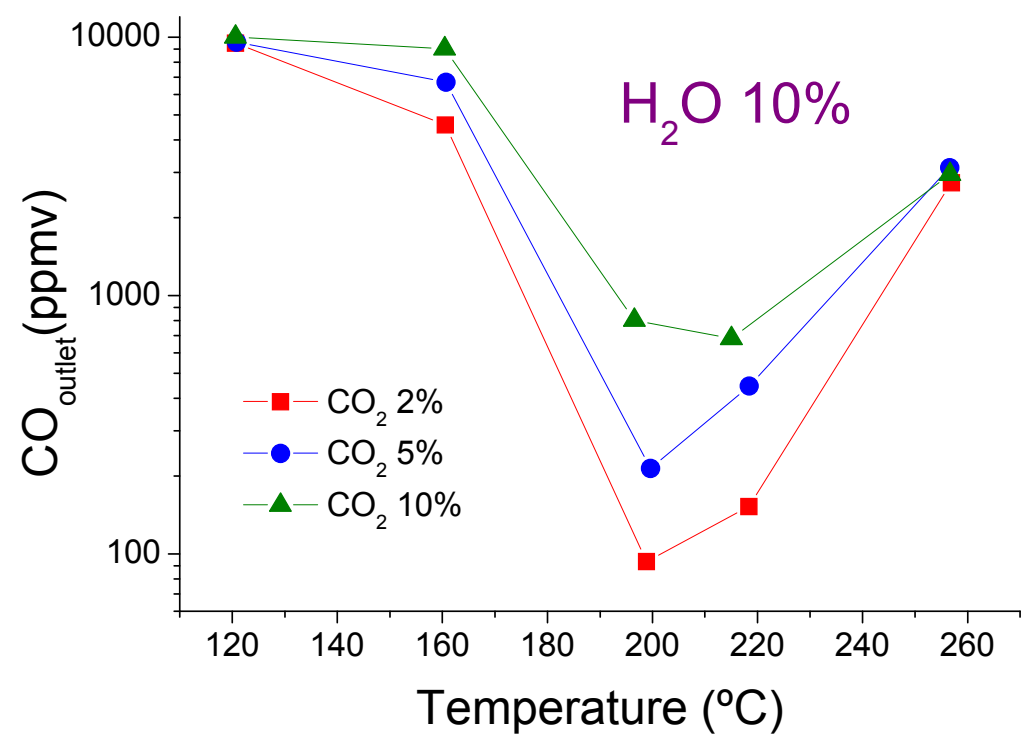

Figure 6 